
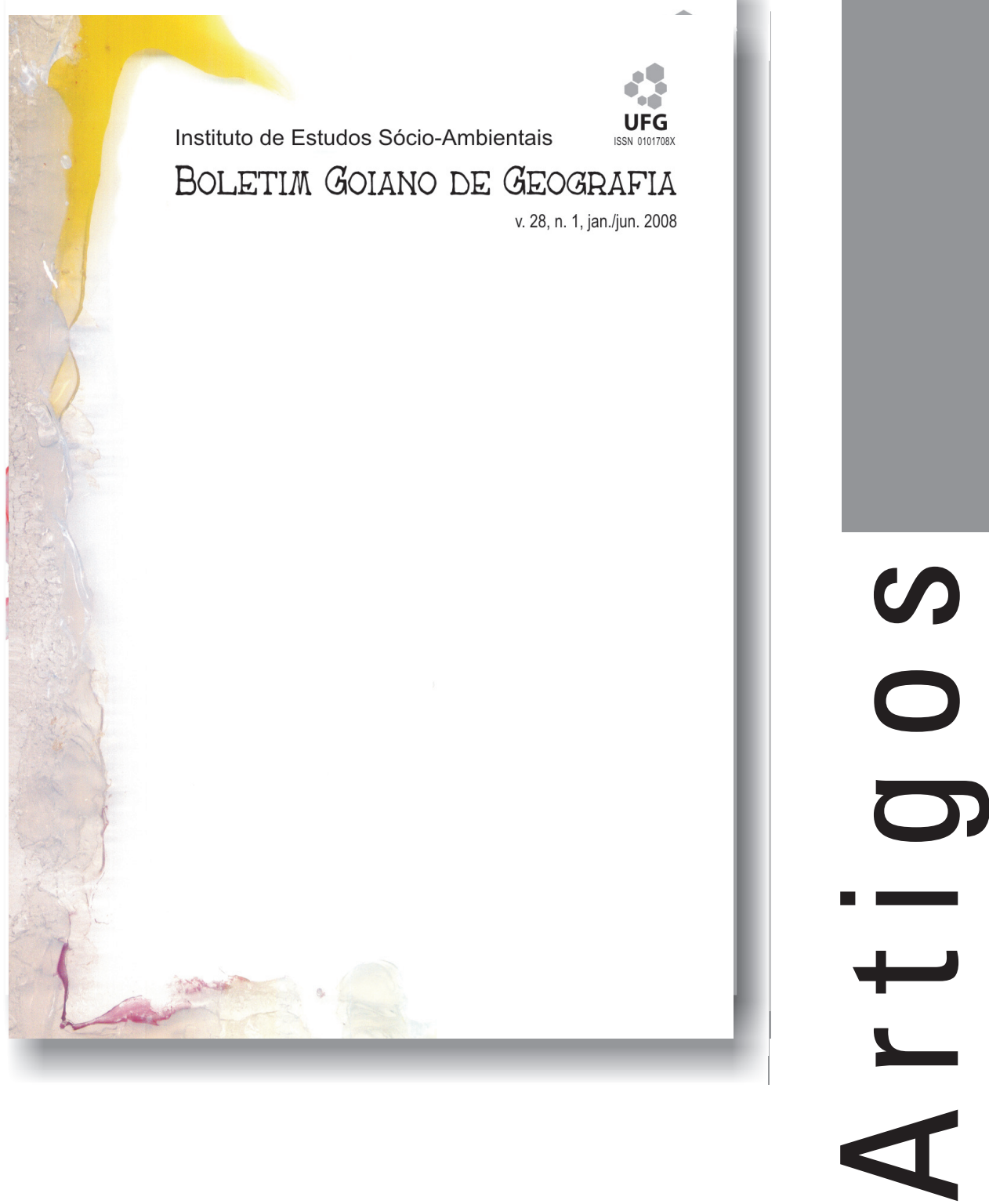


\title{
Evolução das paisagens naturais do Estado do Ceará - Brasil
}

\author{
Evolution of the natural landscapes of the state of the Ceará - Brazil
}

Fátima Maria Soares - UECE

doninha@ufc.br

\section{Resumo}

Esta pesquisa tem por finalidade efetuar resgate de estudos sobre a formação do substrato rochoso e formas de relevo que propiciaram a formação das paisagens naturais no Ceará. Visa, a partir das classificações morfoestruturais e morfoesculturais do relevo em foco, descrever como são constituídas e distribuídas as paisagens em seu espaço territorial.

Palavras-chave: paisagem, espaço geográfico, Ceará

\section{Abstract}

This research has for purpose to effect one rescue of the studies on the formation of the rocky substratum and its relief forms in the State of the Ceará, that had propitiated the formation of there existing the natural landscapes. From the classification of the morfoestruturas and morfoesculturas that compose the relief of this State, to describe as these landscapes are constituted and as they are distributed in its territorial space.

Keys-words: Landscape, geographic space, state of the Ceará 


\section{Introdução}

No campo de investigação científica, a Paisagem Geográfica desperta interesse dos pesquisadores, em especial da Geografia. Apesar dessa linha de pesquisa ter se iniciado no século XIX, nas últimas décadas do século XX ela é retomada por compreender, com maior propriedade a formação e transformação do espaço geográfico, como unidade e singularidade. Esta área de investigação permite, nestes termos, entender os processos de formação da natureza e da sociedade de forma integrada e não compartimentada.

Com o avanço do conhecimento, gerando argumentos, informações e técnicas, atualmente torna-se possível ter noção do uno, sem perda das bases conceituais e científicas geográficas, posto serem tratadas e analisadas como integrantes de um contexto.

Pautando-se nestas premissas serão analisadas as paisagens do Ceará, com suporte na morfologia e estrutura do relevo, estudadas por diversos pesquisadores ao longo do tempo. Nestes termos efetuou-se levantamento bibliográfico sobre a formação das paisagens no Ceará, dando ênfase aos trabalhos sobre o substrato rochoso e seus modelados na superfície continental.

\section{Como se formaram as paisagens naturais do ceará}

A identificação de unidades morfoestruturais e morfoesculturais constitui um dos campos de investigação científica da paisagem geográfica, posto esta encontrar-se submetida ao efeito de processos exógenos e endógenos no planeta, que a modelam e remodelam tornando-a um ambiente singular.

Apesar da noção de paisagem ser de integração da natureza e da sociedade nela contida, a base de sua formação científica é natural, formada pela troca incessante de energia e matéria geradora das diversidades de ambientes.

A estética da paisagem transforma-se em ritmo diferenciado na escala espaço temporal, cuja energia desprendida em sua modificação origina-se das forças naturais e sociais.

A formação da superfície do planeta dá-se a partir da liberação de forças internas que a fraturam e desnivelam, submergindo-a, abrindo fendas que são preenchidas no tempo por sedimentos transportados pela dinâmica exercida pela bacia hidrográfica, agente remodelador da superfície terrestre. 
Embora a força desprendida do centro do planeta, liberando energia e matéria, seja responsável pelas formas de relevo de grandes dimensões, as atividades são controladas pela própria estrutura evolutiva do astro. Sua superfície é protegida por placas que fluam sobre o magma de grande plasticidade e que são submetidas a forças extremas. Movimentadas por tectonismo ou expelidas por vulcanismo, as placas criam formas de orogênese e de epirogênese.

Essa nova tipologia da superfície é retrabalhada continuamente pela ação das águas, quando da formação das bacias hidrográficas, que modelam as rochas em sua descida pelas vertentes, aproveitando as fendas, fraturas e desníveis. Neste processo são carreados, da montante à jusante, sedimentos e material rochoso que, ao serem depositados, redefinem as formas, e portanto, as paisagens.

No esculturamento da superfície terrestre, as condições climáticas contribuem nas transformações da paisagem. Os ciclos de glaciação e aquecimento apresentam-se como agentes atuantes na formação do relevo. A ação das águas na forma sólida ou líquida tem papel preponderante na formação do relevo. Sua mudança de estado permite o arrastamento de materiais de granulometria diferentes, burilando e esculpindo formas.

A ação conjunta dos quatro elementos da natureza (atmosfera, hidrosfera, toposfera e biosfera) aciona mecanismo de correlação em cadeia, formando paisagens. A variaçao da temperatura altera o gradiente pressão e a relação de troca energética entre a atmosfera e litosfera. Seus efeitos determinam o ciclo climático e sua biodiversidade, conforme sua localização geográfica. Assim, materializam-se os ecossistemas oceânicos e continentais, formando ambientes naturais com recursos que permitem a existência e dominação do homem no planeta: usando e transformando a natureza, criando e modificando as paisagens.

No Ceará, as paisagens naturais formadas foram constituídas por: maciços cristalinos e inselbergs; depressões periféricas; chapadas sedimentares; planícies sub-litorânea, fluvial e litorânea (Figura 1).

Essas morfologias foram esculpidas por movimentos tectônicos de epirogênese e orogênese, que fraturaram a crosta, formando graben (cuja extensão possibilitou a formação da rede de drenagem e seus principais rios, como o Jaguaribe). 


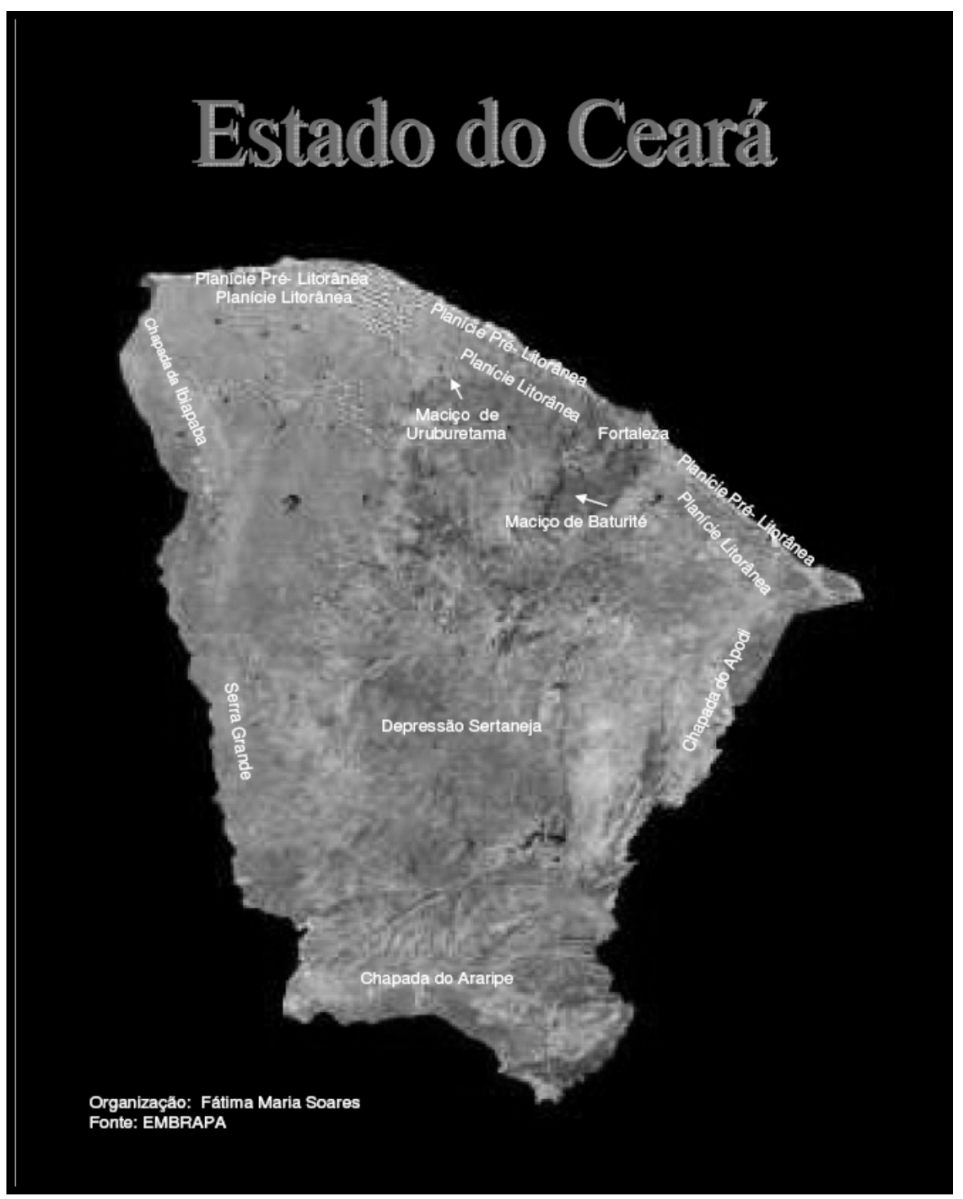

Figura 1. Mapa de Unidade de Paisagem do Ceará (adaptação com base na Unidade de Relevo - SOARES/2007)

Segundo Beurlen (1967), a morfoestrutura do Ceará começou a se delinear a partir do pré-devoniano, período de ruptura dos continentes africano e americano e de formação do Oceano Atlântico. Neste período, este oceano era separado em Norte e Sul, ligando-se o bloco nordestino ao continente africano. O citado bloco encontrava-se sob pressão dos oceanos, tencionando a movimentação isostático da crosta, ocasionando: flexões das estruturas para leste; aberturas de fendas profundas e direcionais; movimentos verti- 
cais separando blocos escalonados (Figuras 2 e 3).

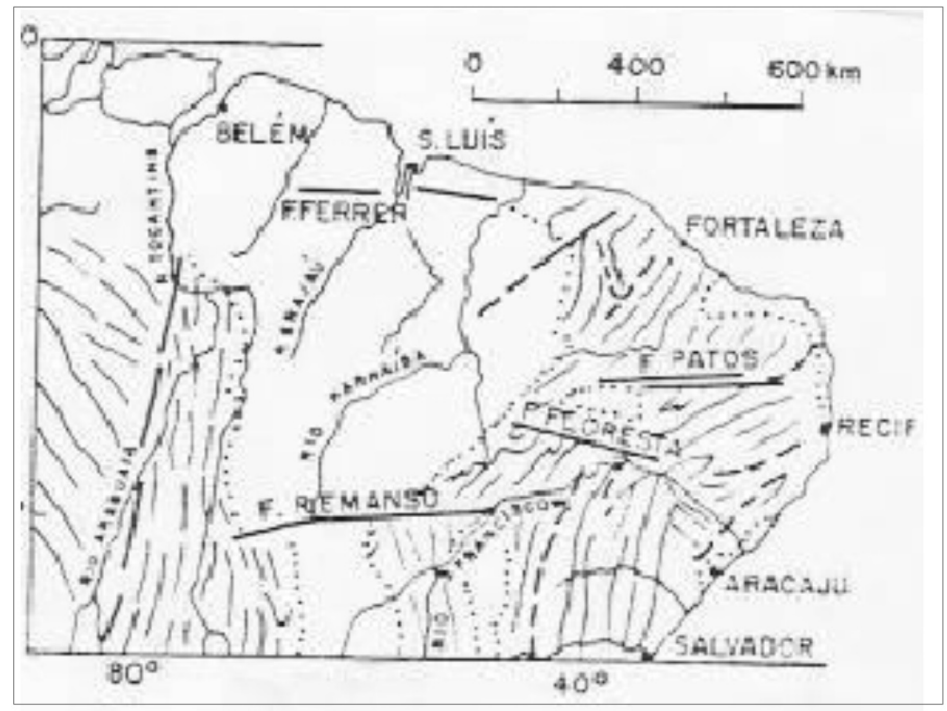

Figura 2 - Estrutura Geológica do Nordeste Brasileiro. Fonte - Kegel (1959)

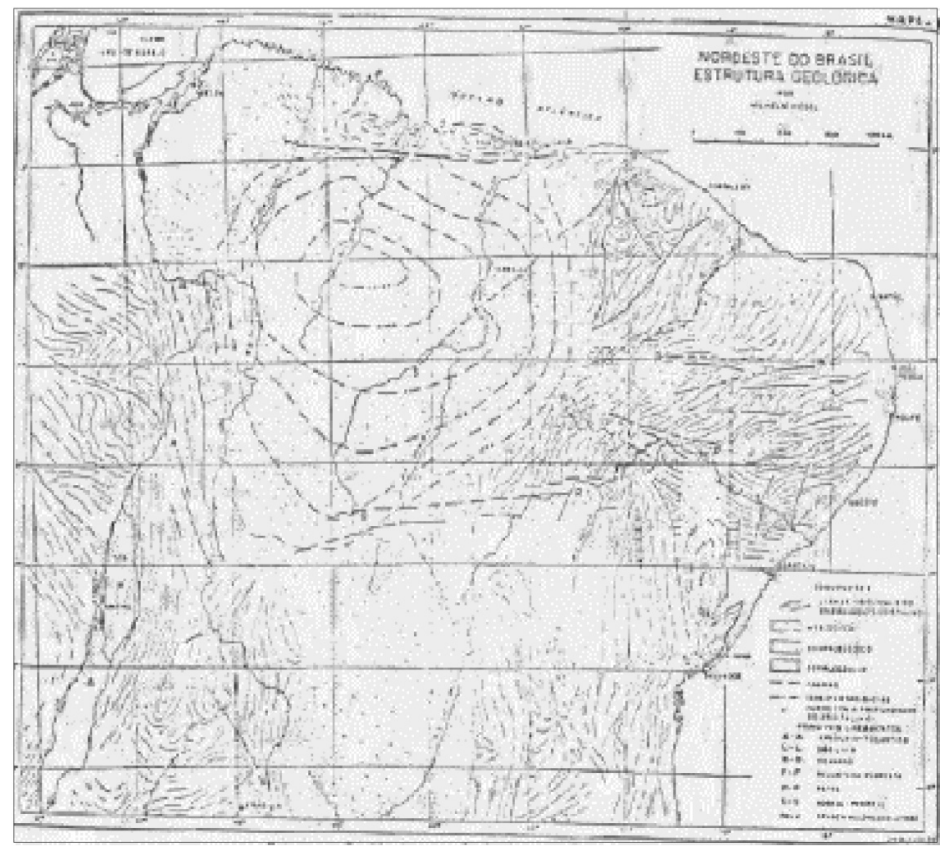

Figura 3 - Estrutura Geológica do Nordeste do Brasil. Fonte - Kegel (1969) 
Sob efeitos climáticos de período mais seco, estabeleceu-se um mar raso que adentrou no continente, formando as estruturas de calcários hoje existentes. Com a intensificação dos movimentos tectônicos, a crosta se rompe em várias direções, com predominância no sentido SW-NE e W-E. Os blocos entre as linhas tectônicas soerguem-se, mantendo uma face elevada e seu reverso inclinando-se suavemente.

No que se refere à presença de calcário na região, diversos estudos são realizados. Kegel (1957) identificou a oeste do rio Açu, no Rio Grande do Norte, os calcários ali depositados como sendo de diferentes períodos. O inferior, depositado em fácies lagunar, argiloso com intercalações de camadas de gipsíferas, ocorrido durante o período de regressão do mar e denominado de calcário Jandaíra. O superior, formado por camadas clásticas, arenoso e puro com conglomerados de folhelhos denominados de Arenito Açu. Este último encontrado na Chapada do Apodi, com reverso situado no Rio Grande do Norte, e sua escarpa para Limoeiro do Norte, no Ceará. Beurlen (1961) ratifica a ocorrência do calcário Jandaíra, identificado por Jacob (1946) nas falésias ao longo do litoral do extremo leste do Ceará, trecho correspondente aos municípios de Icapuí e Acarati.

Na concernente ruptura em várias direções da crosta, merecem destaque os estudos:

Suszczynski (1966, p.386 apud Crandall, 1910), efetuando análise da seqüência litológica do Ceará, identifica fácies litológicas que, segundo ele, possuem a seguinte seqüência: psamítica, pelítica, pelítica-calcária e calcária, dispostas paralelamente E-W. Entre Orós e Banabuí, existem extensas faixas quartzíticas, identificadas como pertencentes às séries Metamórficas: Independência-Sobral e Jaíbara.

A Série Metamórfica Ceará apresenta tensão longitudinal S de 400 km, estendendo-se por Chorozinho, Aruaru, Cunupira, Fronteira e Campos Sales. Neste trecho, ela se junta à Série Metamórfica Independência-Sobral, que se alarga na porção N-S. De Fronteira a Icó, as elevações seguem direção NE-SW, vergando-se para E-W, ou posicionando mais ao N.

A Série Independência-Sobral começa SW/CE, próxima à região Pio IX - Cococi em direção N-S, segue Independência, Reriutaba, Sobral, numa seqüência litológica E-W, com remanescente isolada ao E de Independência. Esta série é contínua em toda sua extensão. As formações de quartzitos formam cristas agudas com afloramento de $300 \mathrm{~km}$, que se juntam ao S/CE na região da Várzea Alegre, Cedro. Em Orós, Banabuiú, as elevações dispõem-se no sentido N-S, inclinando-se para NE na extremidade Norte e para 
SW na extreminade Sul. Cada uma dessas séries metamórficas apresenta estágios diferentes de magmatização e granitização, constituindo-se em uma Unidade Geológica Básica com evolução própria e bem definida no tempo e no espaço.

A Série Jaíbara, no Cretáceo, sofre reativação em movimentos direcionais deslocando blocos para Sudoeste, com espessura em torno de $1.000 \mathrm{~m}$, não mostrando dobramento deformado em falhamentos. Estas falhas, como a do Jaguaribe, foram causadas por compressão do bloco posicionado à NE, quando ainda estava preso ao continente africano, o que provocou levantamento epirogênico e uma distensão da área entre as falhas e a fossa amazônica, esta resultante do rebaixamento epirogênico. Os blocos mais elevados do nordestino vão formar os Planaltos, e as bacias centrífugas.

A Formação Jucá, na alta bacia do rio Jaguaribe, consiste em sedimentos que preencheram a fossa tectônica, na transição da Plataforma Brasileira. A referida sofreu tecto-orogênese, caracterizando-se pela forma alongada na direção do dobramento subjacente.

Almeida (1967) diz que as rochas metamórficas formadoras do Grupo Ceará mostram-se linearmente dobradas no sentido NNE-ENE. Esses falhamentos infiltram-se em discordância com as rochas do Complexo Cristalino, constituído de xistos cristalinos e gnaisses. As rochas do Grupo Ceará são antigos xistos argilosos com quartzitos, arenitos e calcáreos, transformados em mármore. O granito da Serra da Meruoca surge como testemunho da movimentação intensa da crosta que emerge do interior do continente e cujo soerguimento deu origem a esta elevação. Parte dos dobramentos segue na direção NW-NE.

A partir dos movimentos geoanticlinais ocorridos no Ceará, movimentos sinclinais se ergueram na direção NE-SW, apresentando largura aproximada de $170 \mathrm{~km}$ e comprimento de $350 \mathrm{~km}$, dispostos em toda extensão na parte central do Estado (Almeida op. cit p.391). Os Dorsais graníticos, extensos e com pedogêneses espessas, são encontrados em Quixadá, Quixeramobim, Pedra Branca, Serras Maranguape, Baturité, Arara, Serra Feijão, ao Machado, Uruburetana, Serra Marruás, Serras Tamboril, Emanatuba e Boa Viagem.

Em toda sua extensão, do centro para borda E do Estado, os geoanticlinais estão muito dispersos e ligados a processos geológicos diversos, ocorrendo corpos metabásicos-ultrabásicos. Estes estão delimitados por faixas geológicas com ambiente geotectônico primitivo, como os identificados em Fortaleza, Quixadá, Madalena, Pedra Branca, Carrapateiras, Arneirós; Com- 
plexo Magnesiano encontrado em Madalena, Pedra Branca e Carrapateiras (Almeida op cit p: 392).

Nos dobramentos internos geoanticlinal são evidenciadas estruturas de grande complexidade, sistemas de dobramentos perpendiculares em direção NE-SW, sitos em Tamboril, Ebatubá, Boa Viagem, Uruburetama, Itapagé, Irauçuba, Apuiarés, Serra das Vertentes, Trapiá, Sata Quitéria e Catunda.

Ao norte do Estado, o Maciço do Baturité se dispõe na porção W-SW, formado por sedimentos oriundos da Bacia do Meio Norte, distribuídos de forma isolada e esparsa e dispostos em direções diversas. Seqüências litológicas ectiníticas da série metamórfica encontram-se expostas no mesmo sentido, identificadas, a W, em Senador Pompeu e Mombaça, e a SW, em Boa Viagem, São Luís do Curu, Redenção e Aracoiaba.

Almeida (1969) comenta que a evolução geossinclinal cíclica prosseguiu até o quaternário. No NE, as áreas de dobramentos e as bacias intermontanhas são limitadas por falhas - Serra da Ibiapaba. Estas foram preenchidas por duas formações. A primeira, a inferior, composta por arenitos arcósios em pelitos vermelhos, com conglomerados basais. A segunda, a superior, formada por conglomerados polimíticos de origem fanglomerática de intenso magmatismo, cuja deposição deu-se por derrames e intrusões de andesito, riólito, basalto, diabásio, plutões de granito (Serra Meruoca) e granodiorito. A formação da Serra Grande, constituída por arenito branco caolínico, foi oriunda da acumulação de quartzos e feldspatos calinizados, depositados fora da bacia e por uma posterior camada ferruginosa, sucedida pela Formação Pimenteira.

Almeida (op. cit.) concorda com Berder (1965) e Beurlen (1961), quando atribuem a deposição dos calcários, folhelhos e gipsitas, primeiro, a condições estáveis de ação da plataforma continental e, posteriormente, a condições de instabilidade no sentido do litoral. É sob estas mesmas condições ambientais que se formaram as bacias sedimentares localizadas mais ao continente, acumulando-se nos grabens de até 2.500m. Apoiada em Sampaio e Schaller (1968), afirmaram serem esses depósitos evidências observadas na costa. Em 1969, Beurlen e Mabesoone afirmam que os depósitos de gipsita ocorreram quando da ingressão marinha episódica e transitória, cuja inserção em ambiente de águas salobras e clima seco possibilitaram essa formação, em Santana do Cariri, Missão Velha, Portieras e Jardim. Sobre o depósito de calcário, na Chapada do Araripe, dispõe-se o arenito Itapecurú.

A formação das bacias ou manchas do cretáceo superior é conseqüência do depósito de sedimentos cásticos, encontrados na Bacia de Barro (norte 
do Vale do Cariri) e classificados como Formação Brejo Santo-Missão Velha e Mauriti-Tacaratú. Segundo Beurlen e Braun (1965/1966), estas duas formações possuem litologia semelhante à da Serra Grande, na qual se encontram conglomerados de arenitos médios e silicificados com capa laterítica. Para esses autores, o desenvolvimento litológico destas representam relíquias conservadas em blocos afundados de uma única capa sedimentar, análogas à da Chapada do Araripe.

As bacias do Iguatu e dos Peixes, de ampla estrutura anticiclinal, direção W-E, têm, superposta a esta direção, estrutura epirogênica original sinclinal, sendo a atual estrutura imposta por uma inversão das tendências epirogênicas. As bacias apresentam na extremidade setentrional uma capa sedimentar, caracterizada por descontinuidades e relevos testemunhos, como a bacia de Barro, entre Milagres e Icó, preenchida pela Formação Tacarutú, Brejo Santo e Missão Velha. Apresentam-se como blocos inclinados para o sul e na mesma direção cortados por uma falha pronunciada.

Outra relíquia é a bacia de Lavras da Magabeira. Localizada ao norte da capa sedimentar, onde se encontra a Chapada do Araripe, tem-se o vale do Cariri, superfície cristalina que sobe bruscamente para o planalto do Caririaçu e norte de Juazeiro do Norte, entre Milagres e Barros. Nestas áreas, a altitude varia de 800 a 900m, sendo cortada por intensos vales fluviais, com níveis próximos ao da Chapada do Araripe. Na região do Crato, Barbalha, Missão Velha e Milagres, observa-se a constituição da Formação MilagresBrejo Santo, situadas em níveis altimétricos na faixa de 400 a 450m.

Entre os geoanticlinais, encontram-se depressões Laterais que são parte do embasamento cristalino rebaixado ou ao mesmo nível topográfico das elevações de suas circunvizinhanças. As depressões, segundo Ab’ Saber (1956), tiveram sua formação quando o movimento de orogênese reativou a crosta como conseqüência de movimentos epirogenéticos. Constituem áreas deprimidas, circundadas por elevações que, submetidas a mudanças climáticas úmidas, desencadearam um processo rápido de intemperismo químico das rochas. No entanto, a região é submetida temporalmente a mudanças climáticas, de variação entre seca e semi-árida e cuja a ação intempérica decorre das mudanças de temperaturas diurna e noturna, de chuvas sazonais.

Próximo ao litoral, as Formações Infra-Barreira são sedimentos de concreções ferruginosas, com formação de canga na parte superior e presença de seixos de quartzos acumulados, nas proximidades do leito maior dos rios, quando do transporte por águas fluviais. 
Transportados durante o período úmido, os sedimentos originários das rochas cristalinas foram depositados nas áreas depressivas próximas ao litoral, remodelando a paisagem. A rede de drenagem é controlada pelo sistema estrutural, com rios que correm em graben e cujos cursos são colmatados por sedimentos correlatos oriundos do cristalino e formadores dos tabuleiros pré-litorâneos.

No Ceará, observam-se áreas depressivas circundantes posicionadas para o litoral. Estas depressões foram preenchidas por sedimentos correlatos e são identificadas quando ocorrem afloramento. São resultantes de reativação tectônica que elevou esses pacotes de sedimentos e formou as falésias litorâneas. Estas são compostas por sedimentos: coluvionais argilosos, formados em período climático mais seco; aluvionais lixiviados arenosos, depositados em período de clima mais chuvoso.

Em trechos do litoral leste, próximo à fronteira com o Rio Grande do Norte, essas falésias emergem com pacotes de calcário, superposto por sedimentos da Formação do Barreira e dunar. Neste trecho do litoral, as dunas adentram no continente sob a ação dos ventos, transportando sedimentos ao longo do tabuleiro costeiro.

Castro (1979) enfatiza que os ciclos de mudanças climáticas de glaciações com fases mais frias e secas, com domínio das massas polares, à ação de anticiclones subtropicais, desencadeiam processo de erosão mecânica, identificado nos colúvios e sitos nos interflúvios dos canais de pequeno porte.

Ao longo da faixa litorânea, observa-se que as formações dunares obedecem aos ciclos de maior e menor aridez. Tais evidências podem ser verificadas nas formações dunares descaracterizadas do litoral N: Caucaia e Trairi.

Outra evidência da ação climática é seus efeitos no barramento da foz dos rios, formando de um lado, lagoas costeiras permanentes, encontradas em Batoque, no município de Aquiraz e na lagoa do Sal em Beberibe. E de outro lado, lagoas costeiras temporárias, como a lagoa da Barra Mansa, entre Icaraí e Tabuba (Caucaia). No litoral norte, a formação de lagoas ocorre devido barramento da foz dos rios por sedimentos praiais formadores de dunas, identificados no litoral de Itarema, Camocim e Cruz.

No litoral com topografia próxima ao nível do mar, nos períodos mais áridos, observa-se a acumulação de sedimentos alterando o curso dos rios e sua foz. Estes sedimentos formam pequenas restingas, flechas litorâneas e soterram lagoas.

Com base nos estudos anteriormente realizados, santos et al (1972) classificou cinco (5) domínios morfológicos no ceará, subdividindo-os em 10 compartimentos de relevos, discriminados abaixo: 
- Domínio do litoral, incluindo as planícies costeiras e os tabuleiros sobre sedimentos da formação barreira;

- Domínio das depressões interplanálticas e depressões periféricas, refererindo-se às partes rebaixadas da superfície sertaneja;

- Domínio das planícies aluviais, constando trechos alargados dos vales principais;

- Domínio dos planaltos isolados e relevos residuais, subdivididos em três compartimentos de relevo: planaltos isolados, superfícies de planaltos dissecados em morros e patamares, e superfícies de planaltos dissecados em cristas estruturais;

- Domínio dos planaltos sedimentares, constando os compartimentos de relevo cuestiformes e platôs, de relevos sedimentares dissecados e de superfícies conservadas de planaltos, capeadas por detritos ou laterizadas.

A partir da classificação morfoestrutural supramencionada, moreira \& gatto (1981) e prates et. al. (1981), propõem consideração de cinco unidades morfoestruturais: planície litorânea, tabuleiros litorâneos, superfície sertaneja, planaltos residuais e planalto da ibiapaba.

As propostas de classificação morfoestruturais retromencionadas alicerçaram a proposta de souza (1988), que propõe para o ceará três unidades de domínio morfoestruturais:

- $\quad$ Planícies e terraços fluviais, correspondentes aos depósitos sedimentares no cenozóico;

- $\quad$ Chapadas e planaltos, corresponden tes aos sedimentos das bacias sedimentares paleo-mesozóicos, como a chapada do Araripe, chapada do apodi, planalto do ibiapaba serra grande;

- $\quad$ Escudos e maciços antigos, correspondentes aos terrenos cristalinos pré-cambrianos, que formam os planaltos residuais e a depressão sertaneja.

Essas classificações serviram como suporte para a classificação do embasamento cristalino do Ceará por Saadi \& Torquato (1992), indicando duas unidades morfoestruturais:

A primeira unidade resultante de uma complexa distribuição espacial de estruturas geológicas em rochas de natureza ígneo- 
metamórfica do Pré-Cambriano, formadas por três blocos estruturais submetidos a diversos eventos orogenéticos e epirogenéticos, que desencadearam dobramentos, falhamentos, fraturamentos e zonas de cisalhamento na direção NE-SW, associadas às feições dos planaltos sertanejas e aos maciços residuais;

- $\quad$ A segunda unidade é resultante de eventos tectônico-estruturais, direcionados no sentido NW-SE, onde se formaram as depressões sertanejas, fortemente associadas a processos erosivos.

Souza Filho (2000), apoiado nos estudos dos autores citados anteriormente, estabeleceu um quadro litoestratigráfico em mapeamento geológico na folha topográfica SA 24-Y-D-V de Irauçuba, identificando três grandes agrupamentos: Metaplutônicas Pré-Brasilianas, Rochas Supracrustais e Plutônicas Brasileiras.

Na seqüência, Soares (2001) elaborou uma classificação de paisagem, aplicando-a à Bacia Hidrográfica do Curu. Sua base de suporte foi a delimitação da bacia hidrográfica como uma unidade natural, obtida a partir das unidades de relevo, cujo critério fundante foi a morfoestrutura e morfoescultura. Com as unidades delimitadas espacialmente a referida autora inter-relacionou os demais componentes naturais e sociais formadores da paisagem geográfica.

A finalidade da classificação de paisagens proposta consiste em utilizar esta linha de investigação geográfica na leitura e compreensão do espaço no qual se estabelecem as relações natureza-sociedade (agentes do processo de formação e transformação de paisagens).

A paisagem como área de estudo geográfico constitui um campo de observação e análise que permite compreender a formação da superfície da crosta terrestre e seus ecossistemas, bem como as relações estabelecidas com a sociedade.

Desta forma as ações sociais agindo com a natureza se estabelecem como dimensão concreta e perceptiva, modificando e introspectando a paisagem.

A estrutura e a morfologia, bases de sustentação e formação da superfície da crosta terrestre, são percebidas e observadas através das paisagens. A partir desta apreensão, e captação do visível, passa-se à compreensão do invisível. O invisível da paisagem constitui o cerne do visível, pois o que se visualiza é resultante de uma evolução temporal, com forte base natural e social. A paisagem é faceta de um momento histórico espacial, vivido, 
relembrado e registrado através das mais variadas formas de expressões humanas.

\section{Procedimentos metodológicos}

Para desenvolvimento deste estudo, efetuou-se pesquisa Referências em forma de estudo explicativo, com levantamento de base de dados constante em relatórios técnicos e bibliográficos. Conforme o método explicativo, a morfoestrutura e morfoescultura do Estado do Ceará foram utilizadas como parâmetros de identificação das paisagens. Foram utilizados os trabalhos publicados pelos autores: Crandall (1910); Ab’Saber (1956); Beurlen (1957, 1961, 1965, 1966); Kegel (1957); Suszczynski (1966); Almeida (1967, 1969); Mabesoone (1969); Moreira \& Gatto (1981); Prates et al (1981); Souza (1988); Saadi \& Torquato (1992); Souza Filho (2000) e Soares (2001).

\section{Conclusão}

A proposta de realizar resgate dos estudos desenvolvidos no Ceará abarca uma dimensão epistemológica, evidenciando trabalhos clássicos desenvolvidos sobre a temática e indicação dos pressupostos recentes.

O estudo da paisagem na Geografia Física é um campo de conhecimento que utiliza base conceitual ampla, capaz de delimitar as unidades de relevo e determinar sua estrutura e forma: parâmetros da classificação das paisagens.

A consideração dos precursores é essencial no desenvolvimento dos estudos sobre formação da superfície, apresentando-se o Ceará como pano de fundo eles evidenciam as técnicas utilizadas para a identificação das paisagens no passado, que são e importantes na construção das propostas de classificação contemporâneas.

\section{Referências}

Ab’SABER, Aziz Nacib. Regiões de Circundesnudação Pós-Cretácea, no Planalto Brasileiro. São Paulo; Boletim Paulista de Geografia. $\mathrm{n}^{0}$ 1, p.2-21, 1949.

. Depressões Periféricas e Depressões Semi-Áridas no Nordeste do Brasil. São Paulo; Bole-

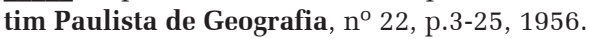


ALMEIDA, F.F.M.de. Diferenciação Tectônica da Plataforma Brasileira. Salvador-BA; Anais do XXIII Congresso Brasileiro de Geologia;. Sociedade Brasileira de Geologia, p.28-46, 1969.

ARAÚJO \& OLIVEIRA JÚNIOR. Mapeamento Geológico e Geomorfológico na Região Estuarina do Rio Pacoti. Rel. Graduação Geologia/UFC. 1992.

ARTHAUD et al As seqüências metassedimentares do Ceará-Central. Anais XL Cong. Bras. de Geologia, Belo horizonte, 1998.

BARBOSA, Otávio. Quadro Provisório das Superfícies de erosão e Aplainamento no Brasil. Campinas, SP; Notícia Geomorfológica, Ano 1, nº 2, p.31-33, 1958.

BEURLEN, Karl. ;MABESSONE, J. M. . Bacias Cretáceas Intracontinentais do Nordeste do Brasil. Campinas, SP; Notícia Geomorfológica, v.9, nº 18, p.1-91, 1969.

BEURLEN, Karl. A Estrutura Geológica do Nordeste do Brasil. Curitiba, PR; Anais do XXI Congresso Brasileiro de Geologia, Sociedade Brasileira de Geologia, p.151-158, 1967.

BRANDÃO, Ricardo de Lima. Zoneamento Geoambiental da Região de Irauçuba - CE. Fortaleza: CPRM, 2003.

CASTRO, C. Morfogênese e sedimentação: Evolução do relevo do Nordeste e seus depósitos correlativos, Campinas, SP; Notícia Geomorfológica, v.19, nº37-38, p.3-27, Dez, 1979.

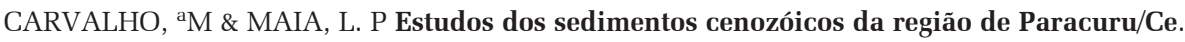
Relatório de Graduação/UFC. 86p. 1990.

COBRA, E. de Q A série Jaíbaras. Soc. Bras. De Geologia. Bol. De Núcleo de Pe. v. 1 n. 1 p: 13211963.

COSTA, W. D Contribuição ao estudo geológico da bacia de Jaíbaras. Esc. Geol PE. UFPE. Arq. De Geologia. N.4 p: 65-89, 1963.

CZAJKA, Willi. Estudos Geomorfológicos no Nordeste Brasileiro. Rio de Janeiro; Revista Brasileira de Geografia. Ano XX, nº2, IBGE, p.135-180, 1958.

FREIRE, G.S. S Geologia marinha da plataforma continental do Estado do Ceará. Tese de mestrado apresentada ao Centro de Tecnologia UFPE. Departamento de Geociências.Recife, 1985.

GRANJEIRO, C.M. M et al. Projeto Planejamento regional integrado e ecologia. Fortaleza. MEC/SUBIM/UECE, 644p, 1983.

ISSLER, R.S \& NASCIMENTO, D A do \& PEREIRA, C. P Rochas alcalinas feldspatóidecas ao Sul de Fortaleza. CE/Natal.Projeto Radam Brasil.Relatório Interno RADAMBRASI, 134-G, 1977

KEGEL, W: SCONMZA, E. P: PINTO COELHO, F. C. Estudo geológico do norte do Ceará. RJ. Div. Geol. Mineralogia. Bol. n. 184, 1958 (vê Bol. 227 n. 47, 1965: Relatório anual 1960).

KEGEL, W. ;SOUZA, E.P. C. e P. Estudos Geológicos do Norte do Ceará. Rio de Janeiro; Boletim, n.184. Divisão de Geologia e Mineralogia. Dept ${ }^{\circ}$ Nacional de Produção Mineral. Ministério da Agricultura, 1957.

KEGEL, W. As inconformidades da bacia do Parnaíba e zonas adjacentes. Div. Geologia e Mineralogia. Bol. n. 160, 1956.

LIMA, Luiz Cruz \& MORAES, Jader Onofre de \& SOUZA, Marcos José Nogueira de. Compartimentação Territorial e Gestão Regional do Ceará. Fortaleza: Ed. Funece, 2000. 
MABESOONE, J.M. \& ROLIM, José Lins. Estratigrafia do Quaternário Continental do Nordeste Brasileiro. Porto Alegre: RS, Anais do XXVIII Congresso de Geologia, Sociedade Brasileira de Geologia, p.59-64, 1974.

MABESOONE, J.M.; CASTRO, Cláudio de. Desenvolvimento Geomorfológico do Nordeste Brasileiro. Recife, PE; Boletim do Núcleo do Nordeste da Sociedade Brasileira de Geologia, $\mathrm{n}^{\circ} 3$, p.5-37, 1975.

MABESSONE, J.M. Panorama Geomorfológico do Nordeste Brasileiro. São Paulo; Geomorfologia, $\mathrm{n}^{\circ} 56,1978$.

MAGALHÃES, A O. A dinâmica da paisagem da panície flúvio-marinha do rio Ceara. Fortaleza. UFC, 1996.

MAIA et al. Estudos dos sedimentos Cenozóicos da Região de Paracuru/Ce. Rel. graduação. Geologia/UFC. 1990.

MEIRELES, A J.A : GURGEL Jr., J.B. Dinâmica costeira em áreas com dunas móveis associados à Promotórios ao longo do litoral Cearense. 38 congressos Bras. De Geol. Balneário de Cambiriú/SE v. 1 p.403.

MEIRELES, A J A. Mapeamento geológico-geomorfológico do Quaternário costeiro de Icapuiextremo Leste do Estado do Ceará. UFPE. Centro de Tecnologia. Pós-Graduação em Geologia Sedimentar. Dissertação de Mestrado, 148p. 1991.

MEIRELES, A J A \& CASTRO, J.WA \& BARBOS, S C \& Araújo, A L. Dinâmica sedimentar entre as praias do Futuro e Iparana. Fortaleza/CE. In: XXXVI Cong. Brás. Geologia. Natal/RN Anais, v.2 p:796-802, 1990.

MORAIS, J O \& MEIRELES, A J A \& FREIRE, G S. Processos hidrodinâmicos e material em suspensão no estuário do Rio Pacoti/Ceará. In: Cong. Bras. Geologia, Belém/PA, anais v.2, p: 551-591 1988.

MORAIS, J.O \& SOUZA, J. V. Transporte e sedimentação das dunas no Município de Fortaleza (Ceará) Est. Sedimentologia. Natal 1 (1): 73-81, 1971.

MORAIS, J.O \& PITOMBEIRA, E. S. Processo Migratório na desembocadura do Rio Maceozinho/Fortaleza. Bol Ciênc. Mar. Fortaleza 27: 1-9.

MORAIS, J. O et al. Contribuição ao escudo geológico-geomorfológico do litoral de Beberibe/ CE. Arg. Ciênc. Mar. Fortaleza 15 (a): 71-78.

MORAIS, J. Os Aspectos de geologia ambiental costeira no Município de Fortaleza. Ce. Tese Prof ${ }^{\circ}$ Titular, 1980.

MORAIS, J. A Evolução Sedimentológico da Enseada de Mucuripe. Ce. Arq. Ciênc. Mar. 21 (1/2): 19-46 1981.

MORAIS, J. O \& MEIRELES, J. A Evidências de variações relativas do Nível do Mar durante o Quaternário no Litoral leste do Estado do Ce. 37 Cong. Bras. De Geologia/SP v.1 p.71.

MORAIS, J. O \& CARVALHO, A M: MAIA, L. P. Dunas da Região Costeira do Estado do Ce. 38 congressos Bras. De Geologia. Balneário Camburiú/SC v. 1 p.404.

MORAIS, J. A Contribuição ao estudo dos beach-rocks do NE do Brasil. Trabal; ho Oceonografia. Recife 9 (11)16p. 1967. 
MOREIRA, M.M.A. M: GATTO, L.C. S Geomorfologia in: Brasil. Ministério das Minas e Energia. Secretaria Geral. Projeto RADAMBRASIL. Folha AS 24 Fortaleza.RJ: Levantamento dos Recursos Naturais, 21, 1981.

PRATES, M: GATTO, L.C. S: COSTA, M. I. P Geomorfologia. IN: Brasil. DNPM-Projeto Radambrasil. Folha SB 24-25 Jaguaribe-Natal, RJ: RADAMBRASIL, 1981.

RODRIGUES, et al. Mapeamento geológico de Planície Costeira de Jericoacoara - Litoral Oeste Cearense. Rel. Graduação. Geologia/UFC. 1995.

SAADI, Allaoua \& TORQUATO, Joaquim Raul. Contribuição à Neoctectônica do Estado do Ceará. Fortaleza. Revista de Geologia, local, v. 5, p. 5-38, 1992.

SANTOS, E. J. et al Mapa geológico do Estado do Ceará. Recife.CPRM, 1972. Escala 1: 500.000 .

SILVEIRA, J. S: VALADÃO, R. C: DOMINGUEZ, J. M. L. Ondas de areia e Dunas Subaquosas geradas por mares: implicações e controvérsias. 37 Congresso Bras. De Geol. SP. v 1 p.194.1992.

SOARES, F. M Unidades do relevo como proposta de classificação das paisagens da Bacia do rio Curu-Estado do Ceará. SP: Tese Doutorado/USP, 2001.

SOUZA, M. J N. et al Geossistemas e Potencialidades dos Recursos Naturais-Serra de Baturité e áreas Sertanejas periféricas MMA/FNMA,FUNCEME, 102p.

SOUZA, Marcos José Nogueira de. Contribuição ao Estudo das Unidades Morfo-estruturais do Estado do Ceará. Fortaleza: Revista de Geologia, v. 1, p. 73-91, jun. 1988.

SOUZA FILHO, O. A de Programa Levantamento Geológico Básico - Projeto Mapa de Previsão de Recursos Hídricos Subterrâneo, Folha AS 24-Y-D-V - Irauçuba. CPRM - Serviço Geológico do Brasil. Fortaleza, 2000.

SUGUIO, K: TESSLER, M. G. Planície de cordões litorâneos. Quaternários do Brasil. Origem e nomeclatura. In: Restinga - Origem, estrutura e processos. Lacerda, L. D. de : Araújo, Cerqueira , R. : Tureq, B (orgs) CEUFF, Niterói, p:453-458,1984.

SUSZCZYNSKI, Edison F. Considerações sobre a evolução tectônica-Orogenética da parte Oriental do Escudo Brasileiro. Recife: PE, SUDENE. Boletim Recursos Naturais, v.4, nº3/4, p.371-416, 1966.

VASCONCELOS, et al. Unidades de correlação da Formação Açu. Bacia Potiguar XXXVI Congresso Bras. Geologia, v. 1 p:227-240, 1990.

VIVEIROS et al. Estudo Paleoambiental Preliminar do Cretáceo da Bacia Potiguar. Ver. Bras. Geociências 17 (2): 123-130 , 1987.

Fátima Maria Soares - professora do Departamento de Geografia da Universidade Federal do Ceará-UFC 